\title{
COMPLIANCE BOUNDARIES FOR TRAIN PROTECTION SYSTEMS
}

\author{
Sam, Aerts*, Leen, Verloock*, Luc, Martens*, and Wout, Joseph* \\ *Department of Information Technology, Ghent University / iMinds \\ Gaston Crommenlaan 8 box 201, B-9050 Ghent, Belgium \\ (email: sam.aerts@intec.UGent.be, fax:+32 933 14899)
}

Running title: TP system compliance boundaries 


\begin{abstract}
COMPLIANCE BOUNDARIES FOR TRAIN PROTECTION SYSTEMS
\end{abstract}

Sam Aerts, Leen Verloock, Luc Martens, and Wout Joseph

Occupational exposure to non-ionizing electromagnetic radiation emitted by train protection (TP) systems operating around $27 \mathrm{MHz}$ is investigated in-situ. In total, five TP systems of two different types, i.e., KVB and TBL1+, are considered. For each type, the boundaries outside which the field levels are in compliance with the ICNIRP guidelines for occupational exposure ("compliance boundaries") are determined. Maximal fields of $4.7 \mathrm{~A} / \mathrm{m}$ and $0.2 \mathrm{kV} / \mathrm{m}$ for KVB, and $51 \mathrm{~A} / \mathrm{m}$ and $1.5 \mathrm{kV} / \mathrm{m}$ for TBL1+ are measured, at distances between 10 and $25 \mathrm{~cm}$ from the respective antennas. Compliance boundaries for occupational exposure are maximally $0.6 \mathrm{~m}$ for KVB to $1 \mathrm{~m}$ for TBL1+, while no specific compliance boundary is needed for the general public. 


\section{INTRODUCTION}

The transposition of the European Directive $(2004 / 40 / E C)^{(1)}$ concerning occupational exposure to non-ionizing radiation will come into effect in 2013. The exposure limits referred to in Directive 2004/40/EC, and concerning the frequencies used by the systems investigated in this study, are based upon the magnetic- and electric-field reference levels and basic restrictions issued by the International Commission on Non-ionizing Radiation Protection $(\text { ICNIRP) })^{(2)}$ for occupational exposure.

Across Europe, more than twenty types of train protection (TP) systems are implemented, all working according to the same principle, i.e., to ensure the safe operation of a train in the event of human failure. Modern TP system variants make use of an antenna placed under the locomotive to receive information sent by electronic beacons installed between the rails, socalled "balises" or "Eurobalises". The TP system antenna radiates a continuous electromagnetic signal (continuous wave, or CW) at a frequency of approximately $27 \mathrm{MHz}$, which is used to energise (or "tele-power") the Eurobalises, which, when energised, transmit data using an uplink FSK ("Frequency-Shift Keying”) modulated signal at 4.23 MHz. This system is in the process of being unified into a single European system, called European Train Control System (ETCS), and works at speeds up to $500 \mathrm{~km} / \mathrm{h}^{(3)}$.

In this study, we investigate two such types of TP systems, namely KVB (Contrôle de Vitesse par Balises), and TBL1+ (Transmission Balise-Locomotive) systems. To our knowledge, no research has been performed yet on the dosimetry of electromagnetic fields (EMF) radiated by these or other TP systems. In fact, there is a general shortage concerning research on sources radiating at frequencies ranging from $300 \mathrm{~Hz}$ to $30 \mathrm{MHz}$. In this frequency range, work has been done concerning e.g., electronic article surveillance systems ${ }^{(4-6)}(58 \mathrm{kHz}$ and 
$\sim 8-15 \mathrm{MHz})$, non-directional beacons for air traffic control $^{(7)}(300-400 \mathrm{kHz})$, high frequency heaters $(13$ and $27 \mathrm{MHz})$ and broadcast antennas ${ }^{(8)}(300 \mathrm{kHz}-50 \mathrm{MHz})$, workers exposed to $0.7-1.5 \mathrm{MHz} \mathrm{EMF}^{(9)}$, and radiofrequency (RF) plastic sealers ${ }^{(10)}(\sim 27 \mathrm{MHz})$. Moreover, a summary of research regarding exposure to EMF in work environments is given in ref. (11).

The objective of this study is to assess for the first time in-situ the occupational exposure to train protection systems, by performing electromagnetic field measurements in the vicinity of five systems of two different types. Furthermore, for each type, compliance boundaries for occupational exposure are determined by comparing the measurements to the limits in the guidelines issued by ICNIRP ${ }^{(2)}$.

\section{MATERIALS AND METHOD}

\section{Investigated TP systems}

The characteristics of the five measured TP systems (three TBL1+ and two KVB systems) and the positions of the locomotives they are mounted on are listed in Table 1, while in Fig. 1 a schematic is shown of how the antennas are mounted to the locomotive. The dimensions of the antennas are $65 \mathrm{~cm} \times 65 \mathrm{~cm} \times 20 \mathrm{~cm}$, and $40 \mathrm{~cm} \times 30 \mathrm{~cm} \times 12 \mathrm{~cm}$, for the KVB and the TBL1+ antennas respectively. The signals from the TP system antennas are continuous waves. No data on output power was available.

The measurements were performed at sites only accessible by railway employees. The three considered TBL1+ mounted locomotives (two manufactured by Siemens, one by Alstom, and denoted as $T i$, with $i=1$ to 3 ) were positioned at different sites: $T 1$ (Siemens) was standing on a regular track; T2 (Siemens) was standing on a track above an inspection tunnel, 
approximately $1.2 \mathrm{~m}$ above the ground; and T3 (Alstom) was standing on an elevated track, approximately $2.5 \mathrm{~m}$ above ground level (Table 1). The two considered KVB mounted locomotives (both manufactured by Alstom, and denoted as $K j$, with $j=1$ to 2) were also positioned at different sites: $K 1$ was standing above an inspection tunnel, $K 2$ on an elevated track, with the heights as mentioned above (Table 1). It should be noted that the closest the general public can come to the antennas is the exterior of the car-body, at $1.5 \mathrm{~m}$ from the antenna centre.

\section{Measurement equipment}

For both magnetic- and electric-field measurements, a Narda PMM EHP-200 probe is used (Narda Safety Test Solutions, Pfullingen, Germany), which has a frequency range of $9 \mathrm{kHz}$ to $30 \mathrm{MHz}$, and a dynamic range of $0.6 \mathrm{~mA} / \mathrm{m}$ to $300 \mathrm{~A} / \mathrm{m}$ for the magnetic field, and $0.02-1000 \mathrm{~V} / \mathrm{m}$ for the electric field. The expanded measurement uncertainty is smaller than 23.4\%. The probe is directly connected via an optical cable to a laptop on which the measurement software is installed.

\section{Measurement procedure}

Firstly, a frequency-domain overview measurement (from $9 \mathrm{kHz}$ to $30 \mathrm{MHz}$, the range of the EHP-200 probe) is performed for each type of TP system, in order to identify the transmission frequency of their respective antennas. The exact frequencies are listed in Table 1.

Secondly, for each of the five considered TP systems, magnetic- and electric-field measurements were performed as a function of the distance to the antennas in three orthogonal directions ( $x, y, z$ in Fig. 1), assuming that the radiation pattern is isotropic. The total electricor magnetic-field value was measured using the following settings: resolution bandwidth 
$(\mathrm{RBW})$ of $1 \mathrm{kHz}$, root-mean-square (RMS) detector mode, and free scan acquisition (as the signal was a continuous wave, and the environment was stable).

Finally, the field values were compared with the guidelines for occupational exposure issued by ICNIRP, i.e., $0.16 \mathrm{~A} / \mathrm{m}$ for the magnetic field, and $61 \mathrm{~V} / \mathrm{m}$ for the electric-field, at $27 \mathrm{MHz}$, and a compliance perimeter was determined for each TP system.

Because of the different positions of the locomotives, a large range of measurements could be performed for each type of TP system (43 for TBL1+ and for $24 \mathrm{KVB}$ ). Since our goal consisted in determining a single compliance boundary per TP system type, all measurements of the same type were examined together.

\section{RESULTS AND DISCUSSION}

\section{General overview of measurements}

In total, 67 measurements were performed of both the magnetic- as well as the electric-field strength in the vicinity of the five considered TP systems; 43 for the TBL1+ system (T1: 13; T2: 20; T3: 10), and 24 for the KVB system (K1: 9; K2: 15). The measurements are summarized in Table 2, listing the distance ranges, the field strength ranges, and the determined compliance boundaries. Scatter plots of the measured field strength as a function of the distance from the respective antennas (ranging from 0.08 to $2.00 \mathrm{~m}$ for TBL, and 0.10 to $1.25 \mathrm{~m}$ for KVB) are shown in Fig. 2 (magnetic field) and Fig. 3 (electric field). 


\section{Magnetic field}

Within $0.25 \mathrm{~m}$ of the centre of the TBL1+ antenna, the magnetic-field strength ranges from approximately $16 \mathrm{~A} / \mathrm{m}$ to nearly $51 \mathrm{~A} / \mathrm{m}$ (Fig. 2), which is the highest magnetic-field strength measured, at $0.13 \mathrm{~m}$ from the antenna's centre. At $1 \mathrm{~m}$, values of $0.05 \mathrm{~A} / \mathrm{m}, 0.06 \mathrm{~A} / \mathrm{m}$, and $0.14 \mathrm{~A} / \mathrm{m}$ are measured for the three locomotives, $T 1, T 2$, and $T 3$ respectively. The lowest measured value is approximately $0.01 \mathrm{~A} / \mathrm{m}$ at $2 \mathrm{~m}$ from the antenna's centre.

The magnetic-field radiated by the KVB antenna shows a similar decrease in strength. However, the field measured within $0.25 \mathrm{~m}$ of the centre of the KVB antenna is nearly 10 times lower, and field values approximately range from $2 \mathrm{~A} / \mathrm{m}$ to $5 \mathrm{~A} / \mathrm{m}$, the highest value, measured at $0.1 \mathrm{~m}$ from the antenna's centre. At $1 \mathrm{~m}$, the magnetic-field strength is $0.025 \mathrm{~A} / \mathrm{m}$, and at $1.25 \mathrm{~m}$, values of $0.01 \mathrm{~A} / \mathrm{m}$ and lower are measured. The fields in the vicinity of $K 1$ and $K 2$ are similar in strength.

We can conclude that the KVB antennas radiate less power than their TBL1+ counterparts. However, smaller differences are also seen between the same TP systems, mounted on different locomotives. E.g., the results for $T 1$ and $T 2$ (both by Siemens) are similar in magnitude, while measurements in the vicinity of $T 3$ (manufactured by Alstom) generally resulted in slightly higher field values. Also noticeable is that, in case of the TBL1+ antenna, the maximum values are not measured closest to the antenna, but rather at a distance of $20 \mathrm{~cm}$ from its centre.

\section{Electric field}

For TBL1+, electric-field values of $300 \mathrm{~V} / \mathrm{m}$ up to $1470 \mathrm{~V} / \mathrm{m}(T 1$, at $0.20 \mathrm{~m}$ from the antenna centre) are measured between 0.1 and $0.25 \mathrm{~m}$ (Fig. 3). The field strength drops below $10 \mathrm{~V} / \mathrm{m}$ 
at $1 \mathrm{~m}$, although values of approximately $15 \mathrm{~V} / \mathrm{m}$ are measured for $T 3$ at $1 \mathrm{~m}$ and $1.35 \mathrm{~m}$. The lowest electric-field strength is $2 \mathrm{~V} / \mathrm{m}$, measured at $2 \mathrm{~m}$ distance.

For KVB, values above $100 \mathrm{~V} / \mathrm{m}$ are only measured up to $0.20 \mathrm{~m}$ from the antennas, and at $1 \mathrm{~m}$, the electric-field strength is already below $5 \mathrm{~V} / \mathrm{m}$. The lowest value measured for KVB is $0.5 \mathrm{~V} / \mathrm{m}$, at $1.35 \mathrm{~m}$ from the antenna.

The electric-field strength shows a similar decrease as the magnetic-field strength; however, farther away from the antenna (from approximately $1 \mathrm{~m}$ on), the curve flattens, and the values are more spread out. This is probably due to disturbances in the electric-field caused by the metallic environment that is the locomotive car-body.

The values measured in the neighbourhood of the KVB antennas are again consistently lower.

\section{Compliance boundaries}

The reference magnetic- and electric-field levels issued by $\operatorname{ICNIRP}^{(2)}$ for occupational exposure are respectively $0.16 \mathrm{~A} / \mathrm{m}$ and $61 \mathrm{~V} / \mathrm{m}$. Both are depicted by striped lines in Fig. 2 and Fig. 3, respectively. Based on these values, compliance boundaries are determined for each of the five TP systems and for both the magnetic and the electric field, and these are listed in Table 2.

For both KVB systems, the magnetic-field strength stays below the reference level of $0.16 \mathrm{~A} / \mathrm{m}$ from a distance of $0.6 \mathrm{~m}$ on; while in case of the TBL1+ system, we find $0.80 \mathrm{~m}$ for $T 1$ and $T 2$, and $1 \mathrm{~m}$ for $T 3$ (Fig. 2). The compliance boundaries for the electric field, on the other hand, are smaller (Fig. 3), with $0.3 \mathrm{~m}$ for both KVB systems, $0.6 \mathrm{~m}$ for $T 1,0.5 \mathrm{~m}$ for $T 2$, and less than $0.8 \mathrm{~m}$ for $T 3$ (no measurements were performed closer to the antenna on T3), indicating that the magnetic field is dominant and should be focused on in further 
investigations, also because of possible disturbance in the electric field due to the metallic measurement environment.

Since the general public cannot come closer than $1.5 \mathrm{~m}$ to the TP system antenna (namely, the exterior of the car-body), and the reference levels for the general public are not exceeded at this boundary for any of the measured TP systems, no specific compliance boundaries for the general public are needed.

\section{CONCLUSIONS}

The exposure to five train protection systems (of two different types) radiating at $27 \mathrm{MHz}$ was investigated in-situ for the first time. Maximal fields of $1471 \mathrm{~V} / \mathrm{m}$ and $51 \mathrm{~A} / \mathrm{m}$ were measured for the TBL1+ system, between 10 and $25 \mathrm{~cm}$ from the antenna, and $235 \mathrm{~V} / \mathrm{m}$ and $4.7 \mathrm{~A} / \mathrm{m}$ for the KVB system, at $10 \mathrm{~cm}$ from the antenna. Occupational exposure reference levels are exceeded close to the antennas, and compliance boundaries were determined: maximally $1.0 \mathrm{~m}$ for the TBL1+ system, and $0.6 \mathrm{~m}$ for the KVB system. A specific compliance boundary for the general public is not needed, as field levels do not exceed the respective reference levels at places accessible for the general public. Further research, through calculations of the specific absorption rate (SAR) to check compliance with ICNIRP basic restrictions is recommended.

\section{FUNDING}

This work was supported by the iMinds RAILS ('Railway Applications Integration and Longterm networkS') project, co-funded by iMinds, a research institute founded by the Flemish 
Government in 2004 (previously known as IBBT), and the involved companies and institutions.

\section{ACKNOWLEDGEMENTS}

W. Joseph is a Post-Doctoral Fellow of the FWO-V (Research Foundation-Flanders) 


\section{REFERENCES}

1. Directive 2004/40/EC. Directive of the European Parliament and of the Council of 29 April 2004 on the minimum health and safety requirements regarding the exposure of workers to the risks arising from physical agents (electromagnetic fields). 18th individual Directive within the meaning of Article 16(1) of Directive 89/391/EEC. Brussels, Belgium: European Union (2004).

2. International Commission on Non-Ionizing Radiation Protection (ICNIRP). Guidelines for limiting exposure to time-varying electric, magnetic and electromagnetic fields (up to $300 \mathrm{GHz})$. Health Phys. 74(4), 494-522 (1998).

3. Alstom. Validation des équipements radio en environnement ferroviaire. (2009). http://www.afcem.org/documents/2009\%20RF\%20HYPER/B_MEYNIEL\%20Validat ion\%20syst $\%$ C3\%A8me\%20radio\%20ferroviaire.pdf. [Last accessed on 14 March 2013].

4. Joseph, W., Vermeeren, G., Verloock, L., Goeminne, F. In situ magnetic field exposure and ICNIRP-based safety distances for electronic article surveillance systems. Radiat. Prot. Dosim. 148(4), 420-427 (2012).

5. Martínez-Búrdalo, M., Sanchis, A., Martín, A., Villar, R. Comparison of SAR and induced current densities in adults and children exposed to electromagnetic fields from electronic article surveillance devices. Phys. Med. Biol. 55(4), 1041-55 (2010).

6. Trulsson, J., Anger, G., Estenberg, U. Assessment of magnetic fields surrounding electronic article surveillance systems in Sweden. Bioelectromagnetics 28(8), 664-666 (2007). 
7. Joseph, W., Goeminne, F., Vermeeren, G., Verloock, L., Martens, L.. In situ exposure to non-directional beacons for air traffic control. Bioelectromagnetics 33(3), 274-277 (2012).

8. Jokela, K., Puranen, L. Occupational RF exposures. Radiat. Prot. Dosim. 83(1-2), 119-124 (1999).

9. Bortkiewicz, A., Gadzicka, E., Zmyślony, M. Heart rate variability in workers exposed to medium-frequency electromagnetic fields. J. Auton. Nerv. Syst. 59(3), 91-97 (1996).

10. Wilén, J., Hörnsten, R., Sandström, M., Bjerle, P., Wiklund, U., Stensson, O., Lyskov, E., Mild, K.H. Electromagnetic field exposure and health among RF plastic sealer operators. Bioelectromagnetics 25(1), 5-15 (2004).

11. Mantiply, E.D., Pohl, K.R., Poppell, S.W, Murphy, J.A. Summary of measured radiofrequency electric and magnetic fields (10 kHz to $30 \mathrm{GHz})$ in the general and work environment. Bioelectromagnetics 18(8), 563-77 (1997). 


\section{LIST OF CAPTIONS}

Table 1: Overview of the measured TP systems.

Table 2: Summary of the magnetic $(\mathrm{H})$ and electric $(\mathrm{E})$ field measurements of the five considered TP systems together with the determined compliance boundaries.

Fig. 1: Coordinate system used for the measurements, with (a) view from below of the locomotive (on rails) and the location of the TP system antenna, and (b) side-view of the locomotive (on rails) and the location of the antenna.

Fig. 2: Magnetic-field measurements of the five considered TP systems as a function of the distance, and comparison with the ICNIRP reference level for occupational exposure of $0.16 \mathrm{~A} / \mathrm{m}^{(2)}$.

Fig. 3: Electric-field measurements of the five considered TP system as a function of the distance, and comparison with the ICNIRP reference level for occupational exposure of $61 \mathrm{~V} / \mathrm{m}^{(2)}$. 


\begin{tabular}{ccccc}
\hline TP system & Frequency (MHz) & Name & Manufacturer & Position \\
\hline TBL1+ & 27.095 & $T 1$ & Siemens & Regular track. \\
& & $T 2$ & Siemens & Inspection tunnel. \\
& & $T 3$ & Alstom & Elevated track. \\
KVB & 27.116 & $K 1$ & Alstom & Elevated track. \\
& & $K 2$ & Alstom & Inspection tunnel. \\
\hline
\end{tabular}

Regular track: ground level; inspection tunnel: $1.2 \mathrm{~m}$ above ground level; elevated track: $2.5 \mathrm{~m}$ above ground level.

Table 1 


\begin{tabular}{|c|c|c|c|c|c|c|c|c|c|}
\hline \multirow[b]{2}{*}{ System } & \multirow[b]{2}{*}{$\begin{array}{l}\text { No. of } \\
\text { meas. }\end{array}$} & \multicolumn{2}{|c|}{ Range of meas. } & \multicolumn{2}{|c|}{ H-field range } & \multirow{2}{*}{$\begin{array}{c}\text { H-based } \\
\text { c.b. } \\
\text { (m) }\end{array}$} & \multicolumn{2}{|c|}{ E-field range } & \multirow{2}{*}{$\begin{array}{c}\text { E-based } \\
\text { c.b. } \\
\text { (m) }\end{array}$} \\
\hline & & $\begin{array}{l}\mathbf{d}_{\min } \\
(\mathbf{m})\end{array}$ & $\begin{array}{c}d_{\max } \\
(\mathbf{m})\end{array}$ & $\begin{array}{c}\mathbf{H}_{\min } \\
(\mathbf{A} / \mathbf{m})\end{array}$ & $\begin{array}{c}\mathbf{H}_{\max } \\
(\mathbf{A} / \mathbf{m})\end{array}$ & & $\begin{array}{c}\mathbf{E}_{\min } \\
(\mathrm{V} / \mathbf{m})\end{array}$ & $\begin{array}{c}\mathbf{E}_{\max } \\
(\mathbf{V} / \mathbf{m})\end{array}$ & \\
\hline$T 1$ & 13 & 0.08 & 2.00 & 0.01 & 26.58 & 0.80 & 2.28 & 1471.70 & 0.60 \\
\hline$T 2$ & 20 & 0.08 & 1.00 & 0.06 & 50.98 & 0.80 & 3.46 & 1445.00 & 0.50 \\
\hline$T 3$ & 10 & 0.80 & 1.35 & 0.03 & 0.28 & 1.00 & 4.86 & 17.92 & $<0.80$ \\
\hline TBL1+total & 43 & 0.08 & 2.00 & 0.01 & 50.98 & 1.00 & 2.28 & 1445.00 & $<0.80$ \\
\hline KI & 9 & 0.10 & 1.25 & 0.01 & 4.27 & 0.60 & 0.47 & 235.49 & 0.30 \\
\hline$K 2$ & 15 & 0.10 & 0.97 & 0.01 & 4.69 & 0.60 & 0.49 & 217.38 & 0.30 \\
\hline KVB total & 24 & 0.10 & 1.25 & 0.01 & 4.69 & 0.60 & 0.47 & 235.49 & 0.30 \\
\hline
\end{tabular}

No. of meas. $=$ number of measurements.

Range of meas. $=$ minimum and maximum distance of the measurements.

H/E-field range $=$ minimum and maximum measured value of the magnetic/electric field.

H/E-based c.b. = compliance boundary based on the magnetic/electric-field measurements

\section{Table 2}



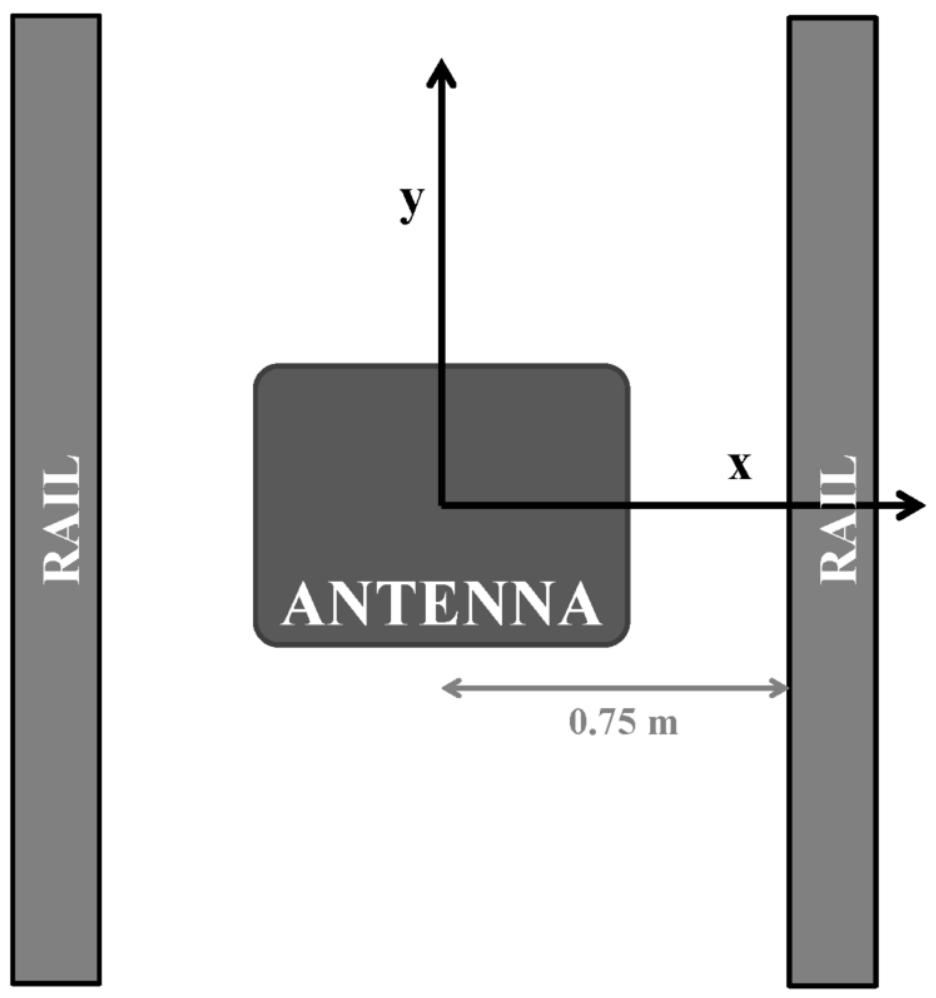

(a)



LOCOMOTIVE

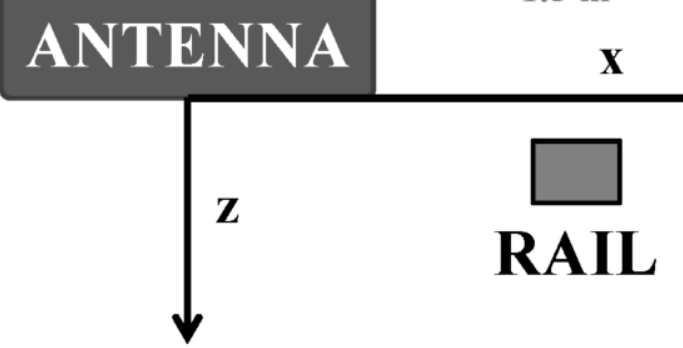

(b)

Fig. 1 


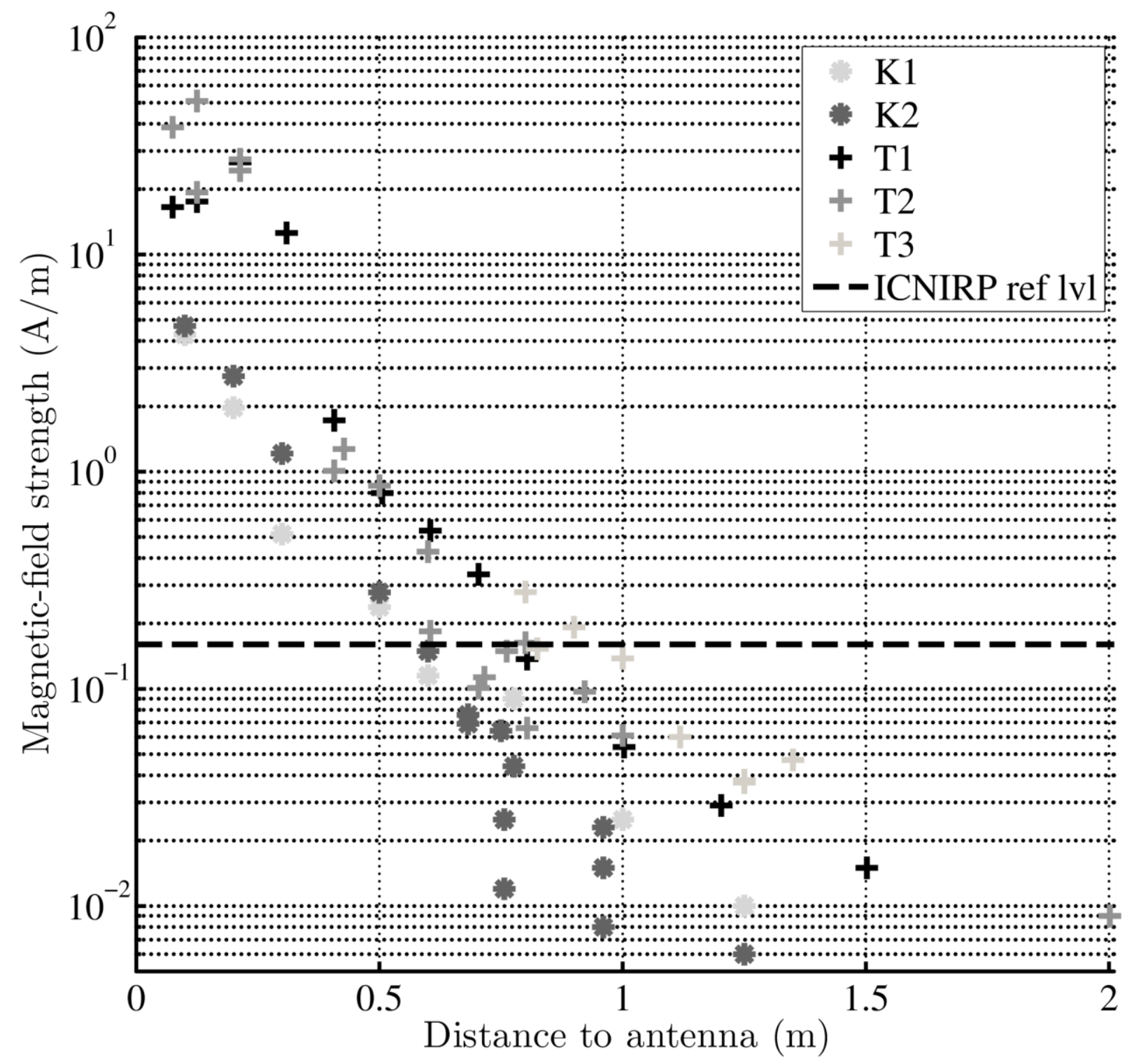

Fig. 2 




Fig. 3 